\title{
Genome Wide Association Study and Next Generation Sequencing: A Glimmer of Light Toward New Possible Horizons in Frontotemporal Dementia Research
}

\author{
Miriam Ciani ${ }^{1,2 \dagger}$, Luisa Benussi ${ }^{1 *}$, Cristian Bonvicini ${ }^{1}$ and Roberta Ghidoni ${ }^{1}$ \\ ${ }^{1}$ Molecular Markers Laboratory, IRCCS Istituto Centro San Giovanni di Dio Fatebenefratelli, Brescia, Italy, ${ }^{2}$ Department \\ of Molecular and Translational Medicine, University of Brescia, Brescia, Italy
}

\section{OPEN ACCESS}

Edited by:

Annakaisa Haapasalo,

University of Eastern Finland, Finland

Reviewed by:

Romina Vuono

University of Cambridge,

United Kingdom

Serena Stanga,

University of Turin, Italy

*Correspondence:

Luisa Benussi

Ibenussi@fatebenefratelli.eu

${ }^{\dagger}$ These authors have contributed equally to this work

Specialty section: This article was submitted to

Neurodegeneration,

a section of the journal

Frontiers in Neuroscience

Received: 29 January 2019 Accepted: 02 May 2019

Published: 16 May 2019

Citation:

Ciani M, Benussi L, Bonvicini C and Ghidoni R (2019) Genome Wide

Association Study and Next Generation Sequencing: A Glimmer of Light Toward New Possible Horizons in Frontotemporal Dementia

Research. Front. Neurosci. 13:506. doi: 10.3389/fnins.2019.00506
Frontotemporal Dementia (FTD) is a focal neurodegenerative disease, with a strong genetic background, that causes early onset dementia. The present knowledge about the risk loci and causative mutations of FTD mainly derives from genetic linkage analysis, studies of candidate genes, Genome-Wide Association Studies (GWAS) and NextGeneration Sequencing (NGS) applications. In this review, we report recent insights into the genetics of FTD, and, specifically, the results achieved thanks to GWAS and NGS approaches. Linkage studies of large FTD pedigrees have prompted the identification of causal mutations in different genes: mutations in C9orf72, MAPT, and GRN genes explain the large majority of cases with a high family history of the disease. In cases with a less clear inheritance, GWAS and NGS have contributed to further understand the genetic picture of FTD. GWAS identified several common genetic variants with a modest risk effect. Of interest, many of these variants are in genes belonging to the endo-lysosomal pathway, the immune response and neuronal survival. On the opposite, the NGS approach allowed the identification of rare variants with a strong risk effect. These variants were identified in known FTD-associated genes and again in genes involved in the endo-lysosomal pathway and in the immune response. Interestingly, both approaches demonstrated that several genes are associated to multiple neurodegenerative disorders including FTD. Thanks to these complementary approaches, the genetic picture of FTD is becoming more clear and novel key molecular processes are emerging. This will foster opportunities to move toward prevention and therapy for this incurable disease.

Keywords: frontotemporal dementia, genome wide association study, next generation sequencing, genetic mutations, genetic rare variants, genetic common variants

\section{INTRODUCTION}

Genetic understanding of neurodegenerative diseases has considerably increased over the years, favoring the identification of possible targets for new potential therapies.

In this review, we report the most recent genetic insights regarding Frontotemporal Dementia (FTD), a focal neurodegenerative disease affecting the frontal and temporal lobes of the brain. 
FTD has a heterogeneous clinical presentation: behavioral abnormalities are prominent in the behavioral variant FTD (bvFTD) (Rascovsky et al., 2011), while language disabilities characterize the Primary Progressive Aphasias (PPAs) (GornoTempini et al., 2011). In addition, the FTD clinical presentation may include movement disorders, such as Progressive Supranuclear Palsy (PSP) and Corticobasal Syndrome (Litvan et al., 1996; Armstrong et al., 2013). Once considered a rare disorder, nowadays FTD is considered a common form of early-onset dementia, with a mean age of presentation under 65 years old (Ratnavalli et al., 2002; Knopman et al., 2004; Coyle-Gilchrist et al., 2016).

Frontotemporal Dementia has a strong genetic background: $30-40 \%$ of FTD patients have a positive family history and, even if a clear autosomal dominant inheritance pattern is often difficult to trace, a high family history is present in roughly $15 \%$ of FTD patients (Rohrer et al., 2009; Wood et al., 2013; Fostinelli et al., 2018). Linkage studies of large families with dominant inheritance pattern for FTD have led to the identification of causative mutations in different genes. Mutations in the microtubule associated protein tau gene (MAPT), located on chromosome 17 and encoding for tau protein, were first identified in 1998 in FTD patients with tau-positive brain inclusions (Hutton et al., 1998; Poorkaj et al., 1998). Genetic research in FTD remained almost silent till 2006, when null mutations in the GRN gene, encoding for progranulin, were found in FTD families with a positive linkage on chromosome 17, in the proximity of MAPT (Baker et al., 2006; Cruts et al., 2006). So far, all identified pathogenic GRN mutations exert a null effect on progranulin protein: therefore, mutations can be easily captured by plasma/serum dosage (Ghidoni et al., 2008, 2012; Finch et al., 2009; Sleegers et al., 2009). In 2011, an additional major genetic determinant was found in families with FTD and Amyotrophic lateral sclerosis (ALS): an intronic expansion of a hexanucleotide repeat in the C9orf72 gene, located on chromosome 9, where previous linkage studies had had identified an FTD/ALS locus (DeJesus-Hernandez et al., 2011; Renton et al., 2011). MAPT, GRN, and C9orf72 mutations, detected in up to $74 \%$ of patients with high family history, represent the most frequent genetic cause of FTD; nowadays 54 and 79 mutations have been described for MAPT and GRN, respectively. ${ }^{1,2}$ Of note, a compound heterozygosity of two MAPT mutations (transmitted by the unaffected parents) was found in a sporadic case, thus highlighting that mutations can be found also in sporadic cases (Anfossi et al., 2011). However, considering FTD patients with lower family history and apparently sporadic cases, mutations in these genes are found in roughly 15\% of cases (Wood et al., 2013; Fostinelli et al., 2018). Additionally, rare FTDcausing mutations have been found in: the Valosin gene $(V C P)$, that was first reported to be mutated in families with hereditary inclusion body myopathy with Paget disease of the bone and FTD; the Charged multivesicular body protein 2B (CHMP2B), with only one proven pathogenic mutation described in 2005 and segregating with FTD; the TAR DNA binding protein (TARDP)

${ }^{1}$ http://www.molgen.ua.ac.be/ADMutations/

${ }^{2}$ https://www.alzforum.org and the Fused in Sarcoma (FUS) genes, two well established ALSassociated genes, playing a minor role also in FTD (Pottier et al., 2015). Together, mutations in these genes account for a large proportion of FTD pedigrees with a high family history of the disease, but only a minority of apparently sporadic patients or patients with a less clear family history.

Thus, deciphering the "missing heritability" of the remaining FTD cases represents one of the main challenges in FTD research. In this direction, Genome-Wide Association Studies (GWAS) and Next-Generation Sequencing (NGS) technologies represent a great potential.

\section{GENOME WIDE ASSOCIATION STUDIES AND THE "COMMON-VARIANTS THEORY"}

For many years, the candidate-gene hypothesis and genetic linkage studies have been the predominant approaches to guide the discovery of FTD-associated genes (Loy et al., 2014). However, these approaches were not enough to fill the gap regarding the missing heritability of most cases. Thus, the candidate-gene studies have been completed with hypothesis-free approaches like GWAS studies, which are based on the analysis of common variants widely distributed in the genome, with a modest effect (Yang et al., 2010; Weiner et al., 2017). Here, the "common-variants theory," which claims that common diseasecausing variants can be identified in every human population that manifest a given disease, became the predominant molecular paradigm. GWAS is based on the use of specific genotyping arrays that interrogate an independent set of variants within the whole genome in related/unrelated individuals, identifying an association between one/more variants and pathological traits (Mishra et al., 2017). This approach has allowed the identification of genetic alterations conferring disease risk revealing that susceptibility factors can be enriched in genes clumped into disease-relevant pathways, offering new angles for research and therapeutic intervention (Ferrari et al., 2015).

A number of genomic regions that may increase the FTD risk has been identified (Table 1).

The importance of the transmembrane protein 106B (TMEM106B) gene, identified by the first GWAS on FTD patients (Van Deerlin et al., 2010), has been confirmed in different studies (Busch et al., 2016; Nicholson and Rademakers, 2016; Gallagher et al., 2017; Rhinn and Abeliovich, 2017). In Van Deerlin et al. (2010), the first team recognized TMEM106B as genetic risk factor in patients with a specific neuropathology. However, when the authors tried to validate this result in a more heterogeneous group of probable FTD cases, lacking post-mortem confirmation, the association of TMEM106B with FTD was lost. Interestingly, van Blitterswijk et al. (2014) identified TMEM106B variants which appeared to alter the C9orf72 phenotype and cause later disease onset. Similarly, specific variants in this gene influence GRN-associated FTD risk, reducing the disease penetrance in GRN mutation carriers (Finch et al., 2011). Latecomer, the FTD risk linked to TMEM106B variants seems to be associated to lysosomal 
dysfunctions, being TMEM106B a lysosomal protein (Nicholson and Rademakers, 2016; Klein et al., 2017). Recently, Pottier replicated the previously reported TMEM106B association and identified a novel genome-wide significant locus at the GDNF family receptor alpha 2 (GFRA2) gene, which encodes for a neurotropic factor with a key role involved in neuron survival and differentiation (Pottier et al., 2018). Moreover, in a recent GWAS study, a link between the C6orf10/LOC101929163 locus and the age of onset in C9orf72 mutation-carriers was identified, supporting the involvement of autophagy in modulating C9orf72 disease (Zhang et al., 2018).

In the largest FTD-GWAS so far, the HLA, RAB38, and Cathepsin C (CTSC) genes were recognized as FTD risk loci, suggesting alterations in immune system, lysosomal and autophagic pathways (Ferrari et al., 2014). An immune-related genetic enrichment in FTD was also described in a very exhaustive study in which a systematic investigation of genetic overlap between immune-mediated diseases and the spectrum of FTD-related disorders was performed. In addition, the authors identified novel susceptibility loci within the Leucine rich repeat kinase 2 (LRRK2), the TBK1 binding protein 1 (TBKBP1), and the PiggyBac transposable element derived (5PGBD5) genes, involved in cell survival, immunity processes and genomic rearrangements, respectively (Broce et al., 2018). Interestingly, GWAS was also used to evaluate shared pathobiology between neurodegenerative disorders. Recently, Karch et al. (2018) highlighted a genetic overlap between FTD and ALS, identifying shared common variants near C9orf72 and the Unc-13 homolog A $(U N C 13 A)$ genes, linked to neuronal vitality. Additionally, the Major histocompatibility complex (HLA), the MAPT, and the Apolipoprotein E ( $A P O E)$ regions were associated to FTD, Alzheimer's disease (AD) and Parkinson's Disease (PD) risk, supporting a genetic pleiotropy in these neurodegenerative diseases (Ferrari et al., 2017). Furthermore, the Elongator acetyltransferase complex subunit 2 (ELP2) gene, a component of the Elongator complex which regulates the activity of RNA polymerase II, was identified as susceptible gene in patients with FTD and FTD-ALS (Dong et al., 2015; Taskesen et al., 2018). Additionally, Mishra et al. (2017) reported an association of $A P O E$ and the Translocase of outer mitochondrial membrane 40 (TOMM40) genes with bvFTD, and the Rho GTPase activating protein 35 (ARHGAP35) and the Serpin family A member 1 (SERPINA1) genes with progressive nonfluent aphasia. Further, they found the $\varepsilon 2$ and $\varepsilon 4$ alleles of $A P O E$ harboring protective and risk increasing effects, respectively, in FTD clinical subtypes (Mishra et al., 2017). TOMM40 provided insight into a metabolic mitochondrial basis for the etiology of FTD (Roses et al., 2016); instead, the novel associations of ARHGAP35 and SERPINA1 with PNFA revealed a potential role of the stress-signaling pathway in FTD pathophysiology (Mishra et al., 2017). In 2015, the RFNG O-fucosylpeptide 3-beta-N-acetylglucosaminyltransferase (RFNG) and the Apoptosis-associated tyrosine kinase (AATK) genes, involved in neuronal genesis and differentiation and axon outgrowth, were recognized as genetic risk factors in an Italian FTD cohort (Ferrari et al., 2015). A GWAS on AD, FTD, and PSP evidenced the ATP binding cassette subfamily A member 7 (ABCA7), the Dysferlin (DYSF), and the PAX interacting protein 1 (PAXIP1) as susceptibility genes (Chen et al., 2015), known to be implicated in lipid metabolism, immune

TABLE 1 | Genome-Wide Association Studies (GWAS) mediated identification of potential pathways contributing to FTD.

\begin{tabular}{|c|c|c|}
\hline Genes & Pathways & References \\
\hline & & Van Deerlin et al., 2010; \\
\hline & & Finch et al., 2011; \\
\hline & & Busch et al., 2016; \\
\hline \multirow[t]{4}{*}{ TMEM106B } & Lysosomal function & Nicholson and Rademakers, 2016; \\
\hline & & Gallagher et al., 2017; \\
\hline & & Rhinn and Abeliovich, 2017; \\
\hline & & Pottier et al., 2018 \\
\hline$H L A$ & Immune response & Ferrari et al., 2014; Broce et al., 2018 \\
\hline RAB38, CTSC & Vesicle-trafficking; lysosomal function & Ferrari et al., 2014 \\
\hline C9orf72, UNC13A & Neuronal survival & Karch et al., 2018 \\
\hline HLA, MAPT, APOE & $\begin{array}{l}\text { Intracellular vesicular trafficking; immune response; } \\
\text { endo/lysosomal processes }\end{array}$ & Ferrari et al., 2017 \\
\hline GFRA2 & Neuron survival and differentiation & Pottier et al., 2018 \\
\hline C6orf10/LOC101929163 & Microglial/autophagy pathways & Zhang et al., 2018 \\
\hline $\begin{array}{l}\text { LRRK2, TBKBP1 } \\
5 P G B D 5\end{array}$ & $\begin{array}{l}\text { Enzyme function; immune response; sequence-specific } \\
\text { genomic rearrangements }\end{array}$ & Broce et al., 2018 \\
\hline ELP2 & RNA transcription & Taskesen et al., 2018 \\
\hline APOE, TOMM4O & Lipid metabolism; metabolic and mitochondrial pathways & Mishra et al., 2017 \\
\hline SERPINA1, ARHGAP35 & Stress-signaling pathway Stress-signaling pathway & \\
\hline RFNG, AATK & Neuronal genesis and differentiation; axon outgrowth & Ferrari et al., 2015 \\
\hline ABCA7, DYSF, PAXIP1 & $\begin{array}{l}\text { Lipid metabolism; immune response; membrane } \\
\text { regeneration and repair: genome stability; Cell survival }\end{array}$ & Chen et al., 2015 \\
\hline
\end{tabular}


processes, mitochondrial abnormalities, and genome stability, respectively (Muñoz and Rouse, 2009; Vincent et al., 2016; Aikawa et al., 2018).

Although GWAS has played an important role in the discovery of risk variants for a specific trait, the identified loci are able to explain only a modest fraction of the predicted genetic variance. Technological limits, including small sample size, allelic heterogeneity and small effect sizes of these genetic variants, in addition to conceptual limitations, once again linked to the inability of common variants in explaining all the still remaining forms without an identified genetic factor, have again influenced the transition to a new approach: from common variants with small effect sizes to rare variants with a higher penetrance.

\section{NEXT-GENERATION SEQUENCING AND THE "RARE-VARIANTS THEORY"}

A further significant contribution toward the knowledge of genetic FTD background came from the "rare-variants theory": rare variants widespread in the genome could represent the missing genetic components for complex diseases. Interestingly, these variants can have determining effects on clinical phenotype, in terms of severity and earlier onset (Xu et al., 2018).

In this scenario, novel methodological issues have raised, due to the unavailability of suitable technologies to unravel the huge number of rare variants throughout the genome. The development of NGS has revolutionized the genetic research, allowing: the analysis of entire genomes (Whole Genome Sequencing, WGS); specific loci or selected candidate genes Targeted Sequencing (TS), or sequencing of exons of all coding genes (Whole Exome Sequencing, WES) (Pottier et al., 2015; Williams et al., 2016; Bonvicini et al., 2019). Thus, in this technological Era, a new opportunity is offered: the genetic analysis is no longer limited to the sequencing of the whole coding sequence of genes known for their implication in a disease, but it is also extended to the parallel analysis of groups of genes acting together in disease-relevant pathways (Boyle et al., 2017).

Thanks to NGS, the "rare variants hypothesis" has been explored also in FTD: discoveries achieved in this field in the last years are reported in Table 2.

Interestingly, a rare variant in the Alpha-synuclein (SNCA) gene, cause of autosomal dominant $\mathrm{PD}$, was observed in

TABLE 2 | NGS mediated identification of rare variants associated with FTD.

\begin{tabular}{|c|c|c|c|}
\hline Mutated gene & Main results & Approaches & References \\
\hline \multirow[t]{2}{*}{ PSEN1, MAPT, APP } & - Identification of known and novel variants in PSEN1, MAPT, and APP & WES & Xu et al., 2018 \\
\hline & - FTD mutation carriers: low age of onset; more rapid progression & & \\
\hline \multirow[t]{3}{*}{ SNCA } & - Identification of a rare variant in SNCA in a bvFTD patient & NGS & Breza et al., 2018 \\
\hline & - Pleiotropic effect of SNCA & & \\
\hline & - Alterations of mitochondrial processes in FTD & & \\
\hline \multirow[t]{3}{*}{ VCP } & - Identification of known and novel variants in VCP both in family members and unrelatedases & WES & Abrahao et al., 2016; \\
\hline & - Pleiotropic effect of $V C P \rightarrow$ heterogeneous clinical features & & Saracino et al., 2018; \\
\hline & $\begin{array}{l}\text { - FTD associated with alterations of ubiquitin system, vesicle transport, proteostasis, neural } \\
\text { vitality, and stress response }\end{array}$ & & Wong et al., 2018 \\
\hline \multirow[t]{3}{*}{ SORT1 } & $\begin{array}{l}\text { - Identification of rare known and novel variants in SORT1 in Belgian, Spanish, Italian, and } \\
\text { Portuguese cohorts }\end{array}$ & NGS & Philtjens et al., 2018 \\
\hline & - SORT1 further confirmed as genetic risk factor for FTD & & \\
\hline & - Defects in protein transport and cellular transduction & & \\
\hline GRN, CSF1R & - Identification of a GRN known pathogenic variant in a bvFTD case & NGS & Kim et al., 2018 \\
\hline \multirow[t]{2}{*}{ AARS2 } & $\begin{array}{l}\text { - Identification of novel variants in two dementia-related genes as CSF1R and AARS2 in bvFTD } \\
\text { patients }\end{array}$ & & \\
\hline & $\begin{array}{l}\text { - Immunity response, inflammatory processes and mitochondrial function involvement in FTD } \\
\text { etiology confirmed }\end{array}$ & & \\
\hline \multirow[t]{4}{*}{ TREM2, GRN } & - Identification of a rare variant in TREM2 & TS & Ng et al., 2018 \\
\hline & - Identification of two novel nonsense GRN mutations & & \\
\hline & - TREM2 and GRN further confirmed as FTD risk genes & & \\
\hline & - Immune pathways and inflammatory responses are altered in FTD & & \\
\hline \multirow[t]{2}{*}{ TYROBP } & - Identification of a rare variant in TYROBP & NGS & Giannoccaro et al., 2017 \\
\hline & - Immune pathway and inflammatory response involvement in FTD etiology confirmed & & \\
\hline \multirow[t]{2}{*}{ TBKBP1 } & - Identification of novel deletions and missense mutations & TS & van der Zee et al., 2017 \\
\hline & - Immune response involvement in FTD etiology confirmed & & \\
\hline \multirow[t]{2}{*}{ SQSTM1 } & - Identification of rare variants in an extended cohort of FTD patients & WES & van der Zee et al., 2014 \\
\hline & - Autophagy-lysosomal alterations in FTD & & \\
\hline \multirow[t]{3}{*}{ CCNF } & - NGS allowed to reveal, in a locus previously identified, a missense mutation in CCNF & NGS, linkage & Williams et al., 2016 \\
\hline & - Combined technologies for a better understanding of diseases & analysis & \\
\hline & - Impairment of protein homeostasis mediated by CCNF & & \\
\hline
\end{tabular}


a bvFTD patient, suggesting alterations in mitochondrial processes also in FTD (Mullin and Schapira, 2013; Breza et al., 2018). A WES study was conducted to perform a genetic exploration in patients with early onset forms of dementia, including FTD. Specifically, Xu et al. (2018) focused on 89 dementia-related causing and susceptible genes, identifying known pathogenic mutations in PSEN1 (Presenilin 1) and $M A P T$, and one novel pathogenic variant in the Amyloid beta precursor protein $(A P P)$ gene. The authors also revealed that all the identified mutations caused dementia with an earlier age of onset and a more rapid disease progression (Xu et al., 2018).

Recently, a group of FTD subjects was screened for different known FTD genes through a WES approach: this study identified two novel and one already known VCP mutations in three patients with a clinical diagnosis of FTD (Wong et al., 2018). In addition, Saracino et al. (2018) analyzed VCP in an FTD cohort, observing seven mutations in unrelated families, including three novel mutations segregating with dementia. Interestingly, a novel rare missense variant in VCP was also described in a FTD subject, member of a family presenting an unusual intra-familiar association of a specific myopathy with ALS and FTD (Abrahao et al., 2016). In all these cases, NGS has permitted to reveal interesting mutations in VCP, implicated in ubiquitin pathways, vesicle transport, proteostasis, neural vitality and stress response (Meyer and Weihl, 2014; Rainero et al., 2017).

By gene target re-sequencing, rare variants within the Sortilin 1 (SORT1) gene were identified in a Belgian FTD cohort. A subsequent study of cohorts sampled in Spain, Italy and Portugal revealed additional non-synonymous variants in European patients. Specifically, SORT1 is a known FTD risk factor: the encoded protein is a neuronal receptor involved in intracellular protein transport and cellular signal transduction (Philtjens et al., 2018).

In sporadic FTD patients without a recognized genetic cause in the well-known FTD related genes (MAPT, GRN, and C9orf72), novel variants were identified in two dementia-related genes, the Colony stimulating factor 1 receptor (CSF1R) and the Mitochondrial alanyltRNA synthetase 2 (AARS2), suggesting new genes to be considered for a genetic FTD diagnosis. CSF1R, which shows important role in innate immunity and inflammatory processes, and $A A R S 2$, involved in mitochondrial functions, highlight alterations of these processes in the FTD etiology (Kim et al., 2018).

Recently, a TS of 12 FTD-associated genes was performed: this study revealed a rare variant in the Triggering receptor expressed on myeloid cells 2 (TREM2) and two nonsense GRN mutations (Ng et al., 2018).

In Giannoccaro et al. (2017), a panel of dementia-associated genes was explored in an Italian group of ALS/FTD pedigrees by using a TS approach: genetic variants in additional ALS and dementia-related genes were found in four pedigrees, including a rare variant in the Tyrosine kinase binding protein (TYROBP) gene. The TYROBP protein, which interacts with several other proteins like TREM2, is specifically involved in immune pathway and inflammatory response (Giannoccaro et al., 2017).

In addition, the TBK1 binding protein 1 (TBKBP1) was screened in a wide cohort of FTD, ALS, FTD-ALS subjects through a TS approach, identifying deletions and missense mutations in this gene involved in immune response (van der Zee et al., 2017).

In van der Zee et al. (2014), rare variants in the Sequestosome 1 (SQSTM1) gene were identified in a cohort of FTD patients, suggesting a role of this gene in the etiology of disease.

Next-Generation Sequencing coupled with conventional approaches is considered the cutting-edge approach for a better understanding of the genetic underpinnings of complex diseases: studies employing NGS have identified rare variants within regions previously prioritized by GWAS, along with novel variants in previously unidentified genes (Williams et al., 2016; Patel et al., 2017). As for GWAS, the linkage analysis has again emerged as an extremely powerful method for the identification of variants implicated in disease in conjunction with WGS filtering approaches (Ott et al., 2015). As regards, in Williams et al. (2016) a genome-wide linkage analysis identified a novel disease locus on chromosome 16p13.3 in a large ALS/FTD cohort. NGS allowed to reveal at this locus a novel missense mutation in Cyclin $\mathrm{F}(C C N F)$ gene, in which specific mutations have been subsequently described in FTDALS subjects (Lee et al., 2018), pointing toward an impairment of protein homeostasis in this complex disorder (Williams et al., 2016; Pan et al., 2017).

\section{CONCLUDING REMARKS}

Overall, this mini-review points up that GWAS and NGS, based on the analysis of different variants with moderateto-strong effect, have concurrently revealed the implication of common molecular pathways in FTD. In particular, these approaches revealed genetic alterations in genes acting together in molecular pathways involved in neuronal-viability and survival, vesicle trafficking, immune and inflammatory response, and energy metabolism. Noteworthy, it has been suggested that defects of all these primary processes could be interrelated at different levels, leading to the degeneration of the whole system and, thus, causing the disease (Ramanan and Saykin, 2013). In particular, multiple studies consolidate the view that immune and endo/lysosomal processes are key players in the pathobiology of these disorders. In future studies, the combination of different molecular approaches also at protein and metabolic levels will definitely help in further clarifying the role of these pathways in FTD pathogenesis and their possible interconnection. In this way, we will foster our potential to move toward effective prevention and therapy for this incurable neurodegenerative disease.

\section{AUTHOR CONTRIBUTIONS}

MC, LB, CB, and RG gave their substantial contribution to conception and design of the manuscript and drafting 
the manuscript, revising it critically for important intellectual content. All authors have approved the manuscript in its present form for publication. All authors agreed to be accountable for all aspects of the work in ensuring that questions related to the accuracy or integrity of any part of the work are appropriately investigated and resolved.

\section{REFERENCES}

Abrahao, A., Abath, N. O., Kok, F., Zanoteli, E., Santos, B., Pinto, W. B., et al. (2016). One family, one gene and three phenotypes: A novel VCP (valosin-containing protein) mutation associated with myopathy with rimmed vacuoles, amyotrophic lateral sclerosis and frontotemporal dementia. J. Neurol. Sci. 368, 352-358. doi: 10.1016/j.jns.2016. 07.048

Aikawa, T., Holm, M. L., and Kanekiyo, T. (2018). ABCA7 and pathogenic pathways of alzheimer's disease. Brain Sci. 8:E27. doi: 10.3390/brainsci80 20027

Anfossi, M., Vuono, R., Maletta, R., Virdee, K., Mirabelli, M., Colao, R., et al. (2011). Compound heterozygosity of 2 novel MAPT mutations in frontotemporal dementia. Neurobiol. Aging 32, 757.e1-757.e11. doi: 10.1016/j.neurobiolaging. 2010.12.013

Armstrong, M. J., Litvan, I., Lang, A. E., Bak, T. H., Bhatia, K. P., Borroni, B., et al. (2013). Criteria for the diagnosis of corticobasal degeneration. Neurology 80, 496-503. doi: 10.1212/WNL.0b013e31827f0fd1

Baker, M., Mackenzie, I. R., Pickering-Brown, S. M., Gass, J., Rademakers, R., Lindholm, C., et al. (2006). Mutations in progranulin cause tau-negative frontotemporal dementia linked to chromosome 17. Nature 442, 916-919. doi: 10.1038 /nature 05016

Bonvicini, C., Scassellati, C., Benussi, L., Di Maria, E., Maj, C., Ciani, M., et al. (2019). Next generation sequencing analysis in early onset dementia patients. J. Alzheimers Dis. 67, 243-256. doi: 10.3233/JAD180482

Boyle, E. A., Li, Y. I., and Pritchard, J. K. (2017). An expanded view of complex traits: from polygenic to omnigenic. Cell 169, 1177-1186. doi: 10.1016/j.cell. 2017.05.038

Breza, M., Koutsis, G., Karadima, G., Potagas, C., Kartanou, C., Papageorgiou, S. G., et al. (2018). The different faces of the p. A53T alpha-synuclein mutation: a screening of Greek patients with parkinsonism and/or dementia. Neurosci. Lett. 672, 136-139. doi: 10.1016/j.neulet.2017. 12.015

Broce, I., Karch, C. M., Wen, N., Fan, C. C., Wang, Y., Tan, C. H., et al. (2018). Immune-related genetic enrichment in frontotemporal dementia: An analysis of genome-wide association studies. PLoS. Med. 15:e1002487. doi: 10.1371/ journal.pmed.1002504

Busch, J. I., Unger, T. L., Jain, N., Tyler, S. R., Charan, R. A., and ChenPlotkin, A. S. (2016). Increased expression of the frontotemporal dementia risk factor TMEM106B causes C9orf72-dependent alterations in lysosomes. Hum. Mol. Genet. 25, 2681-2697. doi: 10.1093/hmg/ ddw 127

Chen, J. A., Wang, Q., Davis-Turak, J., Li, Y., Karydas, A. M., Hsu, S. C., et al. (2015). A multiancestral genome-wide exome array study of Alzheimer disease, frontotemporal dementia, and progressive supranuclear palsy. JAMA Neurol. 72, 414-422. doi: 10.1001/jamaneurol.2014. 4040

Coyle-Gilchrist, I. T., Dick, K. M., Patterson, K., Vázquez Rodríquez, P., Wehmann, E., Wilcox, A., et al. (2016). Prevalence, characteristics, and survival of frontotemporal lobar degeneration syndromes. Neurology 86, 1736-1743. doi: 10.1212/WNL.0000000000002638

Cruts, M., Gijselinck, I., van der Zee, J., Engelborghs, S., Wils, H., Pirici, D., et al. (2006). Null mutations in progranulin cause ubiquitin-positive frontotemporal dementia linked to chromosome 17q21. Nature 442, 920-924. doi: 10.1038/ nature 05017

DeJesus-Hernandez, M., Mackenzie, I. R., Boeve, B. F., Boxer, A. L., Baker, M., Rutherford, N. J. et al. (2011). Expanded GGGGCC hexanucleotide repeat in

\section{FUNDING}

This work was supported by the Italian Ministry of Health (Ricerca Corrente) and the EU Joint Programme - Neurodegenerative Disease Research (JPND2013 www.jpnd.eu) - Funding organization Italy, Italian Ministry of Health.

noncoding region of C9ORF72 causes chromosome 9p-linked FTD and ALS. Neuron 72, 245-256. doi: 10.1016/j.neuron.2011.09.011

Dong, C., Lin, Z., Diao, W., Li, D., Chu, X., Wang, Z., et al. (2015). The Elp2 subunit is essential for elongator complex assembly and functional regulation. Structure 23, 1078-1086. doi: 10.1016/j.str.2015. 03.018

Ferrari, R., Grassi, M., Salvi, E., Borroni, B., Palluzzi, F., Pepe, D., et al. (2015). A genome-wide screening and SNPs-to-genes approach to identify novel genetic risk factors associated with frontotemporal dementia. Neurobiol. Aging 36:2904. doi: 10.1016/j.neurobiolaging.2015. 06.005

Ferrari, R., Hernandez, D. G., Nalls, M. A., Rohrer, J. D., Ramasamy, A., Kwok, J. B., et al. (2014). Frontotemporal dementia and its subtypes: a genome-wide association study. Lancet Neurol. 13, 686-699. doi: 10.1016/S1474-4422(14) 70065-1

Ferrari, R., Wang, Y., Vandrovcova, J., Guelfi, S., Witeolar, A., Karch, C. M., et al. (2017). Genetic architecture of sporadic frontotemporal dementia and overlap with Alzheimer's and Parkinson's diseases. J. Neurol. Neurosurg. Psychiatry 88, 152-164. doi: 10.1136/jnnp-2016-314411

Finch, N., Baker, M., Crook, R., Swanson, K., Kuntz, K., Surtees, R., et al. (2009). Plasma progranulin levels predict progranulin mutation status in frontotemporal dementia patients and asymptomatic family members. Brain 132, 583-591. doi: 10.1093/brain/ awn352

Finch, N., Carrasquillo, M. M., Baker, M., Rutherford, N. J., Coppola, G., DejesusHernandez, M., et al. (2011). TMEM106B regulates progranulin levels and the penetrance of FTLD in GRN mutation carriers. Neurology 76, 467-474. doi: 10.1212/WNL.0b013e31820a0e3b

Fostinelli, S., Ciani, M., Zanardini, R., Zanetti, O., Binetti, G., Ghidoni, R. et al. (2018). The heritability of frontotemporal lobar degeneration: validation of pedigree classification criteria in a Northern Italy cohort. J. Alzheimers Dis. 61, 753-760. doi: 10.3233/JAD-170661

Gallagher, M. D., Posavi, M., Huang, P., Unger, T. L., Berlyand, Y., Gruenewald, A. L., et al. (2017). A dementia-associated risk variant near TMEM106B alters chromatin architecture and gene expression. Am. J. Hum. Genet. 101, 643-663. doi: 10.1016/j.ajhg.2017.09.004

Ghidoni, R., Benussi, L., Glionna, M., Franzoni, M., and Binetti, G. (2008). Low plasma progranulin levels predict progranulin mutations in frontotemporal lobar degeneration. Neurology 71, 1235-1239. doi: 10.1212/01.wnl.0000325058. 10218.fc

Ghidoni, R., Stoppani, E., Rossi, G., Piccoli, E., Albertini, V., Paterlini, A., et al. (2012). Optimal plasma progranulin cutoff value forpredicting null progranulin mutations in neurodegenerative diseases: a multicenter Italian study. Neurodegener. Dis. 9, 121-127. doi: 10.1159/00033 3132

Giannoccaro, M. P., Bartoletti-Stella, A., Piras, S., Pession, A., De Massis, P., Oppi, F., et al. (2017). Multiple variants in families with amyotrophic lateral sclerosis and frontotemporal dementia related to C9orf72 repeat expansion: further observations on their oligogenic nature. J. Neurol. 264, 1426-1433. doi: 10.1007/s00415-017-8540-x

Gorno-Tempini, M. L., Hillis, A. E., Weintraub, S., Kertesz, A., Mendez, M., Cappa, S. F., et al. (2011). Classification of primary progressive aphasia and its variants. Neurology 76, 1006-1014. doi: 10.1212/WNL.0b013e318211 $03 \mathrm{e} 6$

Hutton, M., Lendon, C. L., Rizzu, P., Baker, M., Froelich, S., Houlden, H., et al. (1998). Association of missense and $5^{\prime}$-splice-site mutations in tau with the inherited dementia FTDP-17. Nature 393, 702-705. doi: 10.1038/ 31508 
Karch, C. M., Wen, N., Fan, C. C., Yokoyama, J. S., Kouri, N., Ross, O. A., et al. (2018). Selective genetic overlap between amyotrophic lateral sclerosis and diseases of the frontotemporal dementia spectrum. JAMA Neurol. 75, 860-875. doi: 10.1001/jamaneurol. 2018.0372

Kim, E. J., Kim, Y. E., Jang, J. H., Cho, E. H., Na, D. L., Seo, S. W., et al. (2018). Analysis of frontotemporal dementia, amyotrophic lateral sclerosis, and other dementia-related genes in 107 Korean patients with frontotemporal dementia. Neurobiol. Aging 72:186. doi: 10.1016/j.neurobiolaging.2018. 06.031

Klein, Z. A., Takahashi, H., Ma, M., Stagi, M., Zhou, M., Lam, T. T., et al. (2017). Loss of TMEM106B ameliorates lysosomal and frontotemporal dementia-related phenotypes in progranulindeficient mice. Neuron 95, 281-296. doi: 10.1016/j.neuron.2017. 06.026

Knopman, D. S., Petersen, R. C., Edland, S. D., Cha, R. H., and Rocca, W. A. (2004). The incidence of frontotemporal lobar degeneration in Rochester, Minnesota, 1990 through 1994. Neurology 62, 506-508. doi: 10.1212/01.WNL.0000106827. 39764.7E

Lee, A., Rayner, S. L., Gwee, S. S. L., De Luca, A., Shahheydari, H., Sundaramoorthy, V., et al. (2018). Pathogenic mutation in the ALS/FTD gene, CCNF, causes elevated Lys48-linked ubiquitylation and defective autophagy. Cell. Mol. Life Sci. 75, 335-354. doi: 10.1007/s00018-017-2632-8

Litvan, I., Agid, Y., Calne, D., Campbell, G., Dubois, B., Duvoisin, R. C., et al. (1996). Clinical research criteria for the diagnosis of progressive supranuclear palsy (Steele-Richardson-Olszewski syndrome): report of the NINDS-SPSP international workshop. Neurology 47, 1-9. doi: 10.1212/wnl. 47.1 .1

Loy, C. T., Schofield, P. R., Turner, A. M., and Kwok, J. B. (2014). Genetics of dementia. Lancet 383, 828-840. doi: 10.1016/S0140-6736(13)60630-3

Meyer, H., and Weihl, C. C. (2014). The VCP/p97 system at a glance: connecting cellular function to disease pathogenesis. J. Cell. Sci. 127, 3877-3883. doi: 10. 1242/jcs.093831

Mishra, A., Ferrari, R., Heutink, P., Hardy, J., Pijnenburg, Y., Posthuma, D., et al. (2017). Gene-based association studies report genetic links for clinical subtypes of frontotemporal dementia. Brain 140, 1437-1446. doi: 10.1093/brain/ awx066

Mullin, S., and Schapira, A. (2013). $\alpha$-synuclein and mitochondrial dysfunction in parkinson's disease. Mol. Neurobiol. 47, 587-597. doi: 10.1007/s12035-0138394- $\mathrm{x}$

Muñoz, I. M., and Rouse, J. (2009). Control of histone methylation and genome stability by PTIP. EMBO Rep. 10, 239-245. doi: 10.1038/embor.2009.21

Ng, A. S. L., Tan, Y. J., Yi, Z., Tandiono, M., Chew, E., Dominguez, J., et al. (2018). Targeted exome sequencing reveals homozygous TREM2 R47C mutation presenting with behavioral variant frontotemporal dementia without bone involvement. Neurobiol. Aging 68:160. doi: 10.1016/j.neurobiolaging.2018. 04.003

Nicholson, A. M., and Rademakers, R. (2016). What we know about TMEM106B in neurodegeneration. Acta Neuropathol. 132, 639-651. doi: 10.1007/s00401-0161610-9

Ott, J., Wang, J., and Leal, S. M. (2015). Genetic linkage analysis in the age of whole-genome sequencing. Nat. Rev. Genet. 16, 275-284. doi: 10.1038/nrg3908

Pan, C., Jiao, B., Xiao, T., Hou, L., Zhang, W., Liu, X., et al. (2017). Mutations of CCNF gene is rare in patients with amyotrophic lateral sclerosis and frontotemporal dementia from Mainland China. Amyotroph. Lateral. Scler. Frontotemporal Degener. 18, 265-268. doi: 10.1080/21678421.2017. 1293111

Patel, T., Brookes, K. J., Turton, J., Chaudhury, S., Guetta-Baranes, T., Guerreiro, R., et al. (2017). Whole-exome sequencing of the BDR cohort: evidence to support the role of the PILRA gene in Alzheimer's disease. Neuropathol. Appl. Neurobiol. 44, 506-521. doi: 10.1111/nan.12452

Philtjens, S., Van Mossevelde, S., van der Zee, J., Wauters, E., Dillen, L., Vandenbulcke, M., et al. (2018). Rare nonsynonymous variants in SORT1 are associated with increased risk for frontotemporal dementia. Neurobiol. Aging 66:181. doi: 10.1016/j.neurobiolaging.2018.02.011

Poorkaj, P., Bird, T. D., Wijsman, E., Nemens, E., Garruto, R. M., Anderson, L., et al. (1998). Tau is a candidate gene for chromosome 17 frontotemporal dementia. Ann. Neurol. 43, 815-825. doi: 10.1002/ana.410430617
Pottier, C., Bieniek, K. F., Finch, N., van de Vorst, M., Baker, M., Perkersen, R., et al. (2015). Whole-genome sequencing reveals important role for TBK1 and OPTN mutations in frontotemporal lobar degeneration without motor neuron disease. Acta Neuropathol. 30, 77-92. doi: 10.1007/s00401-0151436-x

Pottier, C., Zhou, X., Perkerson, R. B., Baker, M., Jenkins, G. D., Serie, D. J., et al. (2018). Potential genetic modifiers of disease risk and age at onset in patients with frontotemporal lobar degeneration and GRN mutations: a genome-wide association study. Lancet Neurol. 17, 548-558. doi: 10.1016/S1474-4422(18) 30126-1

Rainero, I., Rubino, E., Michelerio, A., D’Agata, F., Gentile, S., and Pinessi, L. (2017). Recent advances in the molecular genetics of frontotemporal lobar degeneration. Funct. Neurol. 32, 7-16. doi: 10.11138/FNeur/2017.32.1.007

Ramanan, V. K., and Saykin, A. J. (2013). Pathways to neurodegeneration: mechanistic insights from GWAS in Alzheimer's disease, Parkinson's disease, and related disorders. Am. J. Neurodegener. Dis. 2, 145-175.

Rascovsky, K., Hodges, J. R., Knopman, D., Mendez, M. F., Kramer, J. H., Neuhaus, J., et al. (2011). Sensitivity of revised diagnostic criteria for the behavioural variant of frontotemporal dementia. Brain 134, 2456-2477. doi: 10.1093/brain/ awr179

Ratnavalli, E., Brayne, C., Dawson, K., and Hodges, J. R. (2002). The prevalence of frontotemporal dementia. Neurology 58, 1615-1621.

Renton, A. E., Majounie, E., Waite, A., Simon-Sanchez, J., Rollinson, S., Gibbs, J. R., et al. (2011). A hexanucleotide repeat expansion in C9ORF72 is the cause of chromosome 9p21-linked ALS-FTD. Neuron 72, 257-268. doi: 10.1016/j. neuron.2011.09.010

Rhinn, H., and Abeliovich, A. (2017). Differential aging analysis in human cerebral cortex identifies variants in TMEM106B and GRN that regulate aging phenotypes. Cell. Syst. 4, 404-415. doi: 10.1016/j.cels.2017.02.009

Rohrer, J. D., Guerreiro, R., Vandrovcova, J., Uphill, J., Reiman, D., Beck, J., et al. (2009). The heritability and genetics of frontotemporal lobar degeneration. Neurology 73, 1451-1456. doi: 10.1212/WNL.0b013e3181bf997a

Roses, A., Sundseth, S., Saunders, A., Gottschalk, W., Burns, D., and Lutz, M. (2016). Understanding the genetics of APOE and TOMM40 and role of mitochondrial structure and function in clinical pharmacology of Alzheimer's disease. Alzheimers Dem. 12, 687-694. doi: 10.1016/j.jalz.2016.03.015

Saracino, D., Clot, F., Camuzat, A., Anquetil, V., Hannequin, D., GuyantMaréchal, L., et al. (2018). Novel VCP mutations expand the mutational spectrum of frontotemporal dementia. Neurobiol. Aging 72:187. doi: 10.1016/ j.neurobiolaging.2018.06.037

Sleegers, K., Brouwers, N., Van Damme, P., Engelborghs, S., Gijselinck, I., van der Zee, J., et al. (2009). Serum biomarker for progranulin-associated frontotemporal lobar degeneration. Ann. Neurol. 65, 603-609. doi: 10.1002/ana. 21621

Taskesen, E., Mishra, A., van der Sluis, S., Ferrari, R., International FtdGenomics Consortium, Veldink, J. H., et al. (2018). Susceptible genes and disease mechanisms identified in frontotemporal dementia and frontotemporal dementia with amyotrophic lateral sclerosis by DNA-methylation and GWAS. Sci. Rep. 8:7789. doi: 10.1038/s41598-018-21308-x

van Blitterswijk, M., Mullen, B., Nicholson, A. M., Bieniek, K. F., Heckman, M. G., Baker, M. C., et al. (2014). TMEM106B protects C9ORF72 expansion carriers against frontotemporal dementia. Acta Neuropathol. 127, 397-406. doi: 10.1007/s00401-013-1240-4

Van Deerlin, V. M., Sleiman, P. M., Martinez-Lage, M., Chen-Plotkin, A., Wang, L. S., Graff-Radford, N. R., et al. (2010). Common variants at 7p21 are associated with frontotemporal lobar degeneration with TDP-43 inclusions. Nat. Genet. 42, 234-239. doi: 10.1038/ng.536

van der Zee, J., Gijselinck, I., Van Mossevelde, S., Perrone, F., Dillen, L., Heeman, B., et al. (2017). TBK1 mutation spectrum in an extended european patient cohort with frontotemporal dementia and amyotrophic lateral sclerosis. Hum. Mutat. 38, 297-309. doi: 10.1002/humu.23161

van der Zee, J., Van Langenhove, T., Kovacs, G. G., Dillen, L., Deschamps, W., Engelborghs, S., et al. (2014). Rare mutations in SQSTM1 modify susceptibility to frontotemporal lobar degeneration. Acta. Neuropathol. 128, 397-410. doi: 10.1007/s00401-014-1298-7

Vincent, A. E., Rosa, H. S., Alston, C. L., Grady, J. P., Rygiel, K. A., Rocha, M. C., et al. (2016). Dysferlin mutations and mitochondrial dysfunction. Neuromuscul. Disord. 26, 782-788. doi: 10.1016/j.nmd.2016.08.008 
Weiner, D. J., Wigdor, E. M., Ripke, S., Walters, R. K., Kosmicki, J. A., Grove, J., et al. (2017). Polygenic transmission disequilibrium confirms that common and rare variation act additively to create risk for autism spectrum disorders. Nat. Genet. 49, 978-985. doi: 10.1038/ng.3863

Williams, K. L., Topp, S., Yang, S., Smith, B., Fifita, J., Warraich, S. T., et al. (2016). CCNF mutations in amyotrophic lateral sclerosis and frontotemporal dementia. Nat. Commun. 7:11253. doi: 10.1038/ncomms11253

Wong, T. H., Pottier, C., Hondius, D. C., Meeter, L. H. H., van Rooij, J. G. J., Melhem, S., et al. (2018). Three VCP mutations in patients with frontotemporal dementia. J. Alzheimers Dis. 65, 1139-1146. doi: 10.3233/JAD-180301

Wood, E. M., Falcone, D., Suh, E., Irwin, D. J., Chen-Plotkin, A. S., Lee, E. B., et al. (2013). Development and validation of pedigree classification criteria for frontotemporal lobar degeneration. JAMA Neurol. 70, 1411-1417. doi: 10.1001/ jamaneurol.2013.3956

Xu, Y., Liu, X., Shen, J., Tian, W., Fang, R., Li, B., et al. (2018). The Whole exome sequencing clarifies the genotype- phenotype correlations in patients with early-onset dementia. Aging Dis. 9, 696-705. doi: 10.14336/AD.2018. 0208
Yang, J., Benyamin, B., McEvoy, B. P., Gordon, S., Henders, A. K., Nyholt, D. R., et al. (2010). Common SNPs explain a large proportion of the heritability for human height. Nat. Genet. 42, 565-569. doi: 10.1038/ ng. 608

Zhang, M., Ferrari, R., Tartaglia, M. C., Keith, J., Surace, E. I., Wolf, U., et al. (2018). A C6orf10/LOC101929163 locus is associated with age of onset in C9orf72 carriers. Brain 141, 2895-2907. doi: 10.1093/brain/awy238

Conflict of Interest Statement: The authors declare that the research was conducted in the absence of any commercial or financial relationships that could be construed as a potential conflict of interest.

Copyright (c) 2019 Ciani, Benussi, Bonvicini and Ghidoni. This is an open-access article distributed under the terms of the Creative Commons Attribution License (CC BY). The use, distribution or reproduction in other forums is permitted, provided the original author(s) and the copyright owner(s) are credited and that the original publication in this journal is cited, in accordance with accepted academic practice. No use, distribution or reproduction is permitted which does not comply with these terms. 